\title{
Cost Estimates for Operating a Primary Care Practice Facilitation Program
}

Steven D. Culler, $P b D^{1}$

Michael L. Parchman, MD

Raquel Lozano-Romero, $M D^{3}$

Polly H. Noel, PbD ${ }^{4}$

Holly J. Lanbam, $\mathrm{PbD}^{4}$

Luci K. Leykum, $M D^{4}$

Jobn E. Zeber, PbD

'Health Policy and Management, Rollins School of Public Health, Emory University, Atlanta Georgia

${ }^{2} \mathrm{Mac}$ Coll Center for Health Care Innovation Group Health Research Institute, Group Health Cooperative, Seattle, Washington

${ }^{3}$ Department of Family \& Community Medicine, University of Texas Health Science Center-San Antonio, San Antonio, Texas

${ }^{4}$ Department of Medicine, University of Texas Health Science Center-San Antonio, San Antonio, Texas

${ }^{5}$ Scott \& White Healthcare, Center for Applied Health Research, Temple, Texas

Conflicts of interest: authors report none.

\section{CORRESPONDING AUTHOR}

Steven D. Culler, PhD

1518 Clifton Rd NE

Atlanta, GA 30322

sculler@emory.edu

\begin{abstract}
PURPOSE Practice facilitation is widely recognized as a promising method for achieving large-scale practice redesign. Little is known, however, about the cost of providing practice facilitation to small primary practices from the prospective of an organization providing facilitation activities.
\end{abstract}

METHODS We report practice facilitation costs on 19 practices in South Texas that were randomized to receive facilitation activities. The study design assured that each practice received at least 6 practice facilitation visits during the intervention year. We examined only the variable cost associated with practice facilitation activities. Fixed or administrative costs of providing facilitation actives were not captured. All facilitator activities (time, mileage, and materials) were selfreported by the practice facilitators and recorded in spreadsheets.

RESULTS The median total variable cost of all practice facilitation activities from start-up through monitoring, including travel and food, was $\$ 9,670$ per practice (ranging from $\$ 8,050$ to $\$ 15,682$ ). Median travel and food costs were an additional $\$ 2,054$ but varied by clinic. Approximately $50 \%$ of the total cost is attributable to practice assessment and start-up activities, with another 31\% attributable to practice facilitation visits. Sensitivity analysis suggests that a 24-visit practice facilitation protocol increased estimated median total variable costs of all practice facilitation activities only by $\$ 5,428$, for a total of $\$ 15,098$.

CONCLUSIONS We found that, depending on the facilitators wages and the intensity of the intervention, the cost of practice facilitation ranges between $\$ 9,670$ and $\$ 15,098$ per practice per year and have the potential to be cost-neutral from a societal prospective if practice facilitation results in 2 fewer hospitalizations per practice per year.

Ann Fam Med 2013;11:207-211. doi:10.1370/afm.1496

\section{INTRODUCTION}

$\mathrm{I}$ mproving primary care practices in the United States is a widely agreed-upon strategy for improving access to and quality of health care without increasing costs. ${ }^{1-6}$ Practice facilitation is a promising and practical method for supporting practice redesign in small primary care settings. ${ }^{7-10}$ Often improvements targeted by practice facilitation programs result in improved quality of care and process outcomes. A recent systematic review found that practices receiving practice facilitation are 2.76 (95\% CI, 2.18-3.43) times more likely to make changes necessary to implement evidence-based guidelines and concludes that it is a robust intervention for improving primary care. ${ }^{11}$

Although practice facilitation is widely recognized as a promising method for achieving large-scale practice redesign, little is known about its cost. Developing cost estimates associated with administering a practice facilitation program in local or regional primary care settings is necessary to be able to plan for the supporting infrastructure. ${ }^{12}$ The purpose of this article is to report the variable costs (those costs that occurred while carrying out all practice facilitation activities) of providing prac- 
tice facilitation to small primary care practices from the perspective of an organization supporting the program.

\section{METHODS}

\section{Setting and Intervention}

Our study was conducted in small (1 to 4 clinicians) primary care clinics or practices in south Texas. The design and intervention of this trial have been previously reported. ${ }^{13}$ The intervention focused on improving diabetes outcomes by implementing the components of the Chronic Care Model over 12 months. After the initial assessment, facilitators delivered a feedback report with a set of recommended improvement strategies specific to each practice. In subsequent meetings, a facilitator met with the practice to identify additional opportunities for improvement, assess current practice needs, and discuss successful implementation strategies used by other clinics. The facilitators conducted at least 6 practice facilitation meetings with the members of each clinical practice during the 12 -month intervention period.

\section{Data Collection}

Each week facilitators recorded time, mileage, and materials associated with all activities. Categories of facilitation activities were created so that the time and cost could be consistently recorded across practices by all facilitators. Spreadsheets were reviewed by study coordinators and facilitators to assure consistent resource categorization and to update spreadsheets for new activities during the study period.

Fixed or administrative overhead costs, such as for office space, computers, cell phones, or supervision and management activities, were not collected. The scope of this study's facilitation effort (19 practices) was too small to provide reliable estimates of these costs.

Facilitation activities undertaken for research purposes only were identified and not included in the analysis. Study investigators independently reviewed the spreadsheet and data elements and categorized activities as either purely related to research or necessary for effective practice facilitation. Areas of disagreement were discussed with the facilitators and consensus reached.

\section{Time and Cost Assumptions}

All facilitator time was rounded to the nearest quarterhour, and a wage of $\$ 30$ per hour was used to convert practice facilitators' reported time into a wage cost.

This cost approximates the annual wage plus benefits in the study's local labor market. Food expenses were estimated at $\$ 10$ per person. Finally, it was assumed that every visit to a clinic started at the practice facilitator's office and was round trip. Travel cost was calculated by multiplying trip mileage by $\$ 0.50$ per mile (the federal income tax reimbursement rate at the time of the study).

To demonstrate the impact of varying the hourly wage assumption, we estimated the total variable cost of practice facilitation assuming that practice facilitators earned $\$ 40$ and $\$ 50$ per hour. In addition, to provide some insight into the impact of changing the intensity of practice facilitation, we simulated the cost of facilitation activities for 12 and 24 practice facilitator's visits based on the original $\$ 30$ hourly wage by multiplying the average variable cost per visit and average cost of travel and food per visit by 12 and 24 visits

\section{RESULTS}

Selected practice characteristics (full-time equivalent staff, health information technology, patient volume, and payer mix) are displayed in Table 1. Practices

\section{Table 1. Selected Baseline Characteristics of Clinical Practices Receiving Practice Facilitation Activities ( $N=19$ practices)}

\begin{tabular}{lccc}
\hline Characteristic & Mean (SD) & Median & Range \\
\hline FTE personnel, No. & $1.05(0.22)$ & 1.0 & $1-2$ \\
Physicians, medical and osteopathic & $0.31(0.58)$ & 0.0 & $0-1$ \\
Physicians assistants & $0.11(0.31)$ & 0 & $0-1$ \\
Nurse practitioners & $6.1(2.4)$ & 5 & $2-12$ \\
Office staff & & & \\
Health information technology, \% & 94.7 & - & - \\
$\quad$ Electronic patient scheduling & 63.2 & - & - \\
Electronic clinical patient management & 31.6 & - & - \\
Electronic prescribing & 31.6 & - & - \\
$\quad$ Electronic referral request submission & & & \\
Patient volume per clinician & $24.0(4.9)$ & 25 & $18-35$ \\
Office visits per day per FTE clinician, No. & $4.08(7.39)$ & 0 & $0-25$ \\
Hospital visits per week, No. & 21.2 & - & - \\
Practice routinely measures patient satis- & & & \\
$\quad$ faction, \% & & 25 & $0-80$ \\
Patient insurance status, No. & $30.5(22.9)$ & 5 & $0-80$ \\
Medicare & $14.5(20.1)$ & 0 & $0-48$ \\
Medicaid & $9.6(17.0)$ & 30 & $0-87$ \\
Capitation & $33.4(31.1)$ & 5 & $0-100$ \\
Fee for service & $11.9(22.0)$ & & \\
Uninsured & & \\
\hline FTE = full-time equivalent. & & & \\
\hline
\end{tabular}




\section{Table 2. Variable Cost of Practice Facilitation and Selected} Facilitation Activities

\begin{tabular}{lr}
\hline Activity & $\begin{array}{c}\text { Median } \\
\text { Cost, } \mathbf{\$}\end{array}$ \\
\hline Key facilitation activity & 7,626 \\
Total variable cost of all practice facilitation activities & 2,054 \\
Total travel and food cost of practice facilitation activities & 9,670 \\
Total variable cost & \\
Selected facilitation activity & \\
Part A: variable cost of selected start-up activities & 375 \\
Facilitation orientation cost & 3,075 \\
Direct time cost of completing baseline evaluation report & 1,067 \\
All other variable cost of start-up activities & 4,517 \\
Total cost of all start-up activities & \\
Part B: variable cost for practice facilitation activities & 474 \\
Cost for providing baseline feedback report & 660 \\
Cost of all facilitation materials provided & 1,315 \\
Cost of all actual practice facilitation activities during study & 2,449 \\
Total cost of practice facilitation & \\
Part C: variable cost of monitoring following the practice facilitation & 448 \\
Total cost of all monitoring activities & \\
Part D: travel and food cost associated by practice facilitation activities & \\
Total for start-up activities & 1,040 \\
Total for practice facilitation activities & 919 \\
Total for monitoring activities & 95 \\
Total travel and food cost & 2,054 \\
\hline a Travel times reflect distance between clinic and facilitator's office, the number of trips, and number of \\
facilitators attending the meeting.
\end{tabular}

\section{Table 3. Simulated Variable Cost of Practice Facilitation}

\begin{tabular}{lc}
\hline Simulation cases & $\begin{array}{c}\text { Median } \\
\text { Cost, \$ }\end{array}$ \\
\hline $\begin{array}{l}\text { Simulation 1: Impact of change in hourly wage of practice facilitator } \\
\text { on total facilitation cost }\end{array}$ & 11,797 \\
$\quad$ Estimated total facilitation cost at $\$ 40$ per hour wage & 13,875 \\
$\quad$ Estimated total facilitation cost at $\$ 50$ per hour wage & 11,085 \\
Simulation 2: Impact of change in number of facilitation visits & 15,098 \\
$\quad$ on total facilitation cost & \\
Estimated total facilitation cost with 12 practice facilitation visits & \\
\hline Estimated total facilitation cost with 24 practice facilitation visits & \\
\hline Note: All simulation cost estimates include the variable cost of food or travel. & \\
\hline
\end{tabular}

tem design changes, such as group diabetes visits or point-of-care hemoglobin $\mathrm{A}_{1 \mathrm{c}}$ testing.

Median variable costs of selected facilitation activities can be found in Table 2. Supplemental Table 1 (available at http://annfammed.org/ content/11/3/207/suppl/DC1) contains a detailed breakout of the median cost and the range of costs for selected key components of practice facilitation activities. The median total variable cost of all practice facilitation intervention activities from start-up through monitoring, including travel and food, was $\$ 9,670$ per practice (range $=\$ 8,050$ to $\$ 15,682$ ) . More than $46 \%$ of the costs was spent on start-up activities to initiate practice facilitation $(\$ 4,517$, range $=\$ 4,178$ to $\$ 5,589$ per practice [see Supplemental Table 1]). Of this start-up cost, almost $65 \%$ was attributable to baseline practice evaluation activities, with the 2 largest cost components being the chart audit $(\$ 1,298)$ and preparing the baseline feedback report $(\$ 1,095)$.

The median total variable cost of all facilitation meeting activities (Table 2, part B) was $\$ 2,449$ per clinic (range $=\$ 2,194$ to $\$ 4,062$ ). The total direct practice facilitation activity cost was split between cost of preparing and presenting baseline feedback reports to the clinics ( $40 \%$ of costs) and the cost of all practice facilitation meeting activities with clinics $(60 \%$ of costs) during the remainder of the study period.

The median total cost of ongoing monitoring and follow-up reporting (Table 2, part C) was $\$ 448$ (range $=\$ 319$ to $\$ 615)$. Finally,

attempted to implement a variety of improvement strategies. Sixteen practices targeted improvements in patient self-management support and activation, such as providing patients with logbooks to track outcomes and placing educational posters and reading materials in examination rooms. Approximately one-half of the practices initiated or increased the number of staff meetings to discuss clinical quality improvement activities, and 9 of 19 practices initiated short (3- to 5-minute) daily staff huddles to communicate daily workflow plans. Another 8 practices implemented delivery sys- median travel and food cost (Table 2, part D) was an additional $\$ 2,054$, but varied by clinic based mainly on the actual distance to the clinic and the number of staff members participating in practice facilitation activities at each clinic.

Table 3 displays the median cost estimates for the simulations. Increasing the hourly wage of practice facilitators from $\$ 30$ to $\$ 40$ per hour increased the total median variable cost (with travel or food) from $\$ 9,670$ to $\$ 11,797$, a $22.0 \%$ increase. Cost estimates for raising the hourly wage to $\$ 50$ per hour are also 
shown. Doubling the number of facilitation meetings from 6 to 12 only added $\$ 1,415$ to median total variable costs of all practice facilitation activities. Increasing the number of visits to 24 increased estimated median total variable costs of all practice facilitation activities by $\$ 5,428$, for a total of $\$ 15,098$.

\section{DISCUSSION}

The median total cost of a 6 -visit practice facilitation intervention focused on improving chronic illness care in small primary care practices is approximately $\$ 9,670$ per practice per year. This finding is consistent with a prior estimate by Hogg and colleagues for a facilitation intervention to improve preventive services. ${ }^{12}$ Approximately $47 \%$ of the total practice facilitation costs were attributable to practice assessment and start-up activities, with another $25 \%$ attributable to facilitation visits. Although some may question the necessity of the assessment and start-up costs, many, if not all, of these small independent practices had no performance data. For buy-in to occur, it was critical to provide practices with a picture of their current clinical performance and operations, which required auditing medical records, undertaking surveys, and conducting interviews with practice staff. During practice assessment, the facilitator was also able to establish a relationship of trust and respect with staff and clinicians, which was essential for effective facilitation. ${ }^{14,15}$

If the practice facilitation program were undertaking in a larger health care system in which there were 60 primary care practices, for example, at $\$ 9,670$ per practice per year, total variable costs over the first year would be approximately $\$ 580,000$. Assuming an overhead cost rate of $40 \%$, the total costs would be $\$ 812,000$ in the first year of the program. This study found, however, that much of the cost of practice facilitation is devoted to start-up and practice assessment. As a result, the costs of ongoing facilitation activities in subsequent years are likely to be much lower.

Many improvements targeted by practice facilitation programs in primary care may result in a decrease in future hospitalizations. In fact, early findings from patient-centered medical home demonstrations show reductions in emergency department visits and avoidable admissions. ${ }^{16-18}$ Medicare ProPAC reported in 2009 (during the study period) that acute care hospital cost per discharge on average ranged from $\$ 5,800$ to $\$ 6,400 .{ }^{19}$ Using the lower of these estimates, the break even case for returning variable cost of practice facilitation activities from a delivery system perspective is a reduction in hospitalizations or readmissions by 2 per year per practice.
These cost estimates are for variable practice facilitation costs only and do not include the cost of facilitator training or the fixed costs of office rent, utilities, information technology, etc, which are likely to vary by geographic location. In addition, this study was limited to a single geographic area in one state, which may reduce the generalizability of the cost estimates. We attempted to address this limitation with a sensitivity analysis that varies facilitator's salaries and travel time estimates. Finally, it is important to note that this study did not address the cost to the practice of implementing improvements designed to improve diabetes care and outcomes in response to facilitation. It is likely that these costs are not negligible, as staff and clinicians both invested time meeting with the facilitator and implementing changes between the facilitation visits, time supported by their salaries that did not contribute toward direct patient care.

In conclusion, depending on the intensity of the intervention, the median cost of practice facilitation is between $\$ 9,670$ and $\$ 15,098$ per practice per year, the cost of between 2 and 3 hospitalizations per year.

To read or post commentaries in response to this article, see it online at http://www.annfammed.org/content/11/3/207.

Key words: health economics; practice facilitation; primary care practice transformation

Submitted August 8, 2012; submitted, revised, November 9, 2012; accepted November 20, 2012.

Funding support: This study was funded by a grant from the National Institute of Diabetes, Digestive, and Kidney Disorders (R18 DK 075692), This work was also supported with resources and the use of facilities at the Audie L. Murphy Veterans Hospital, Veterans Health Administration, Department of Veterans Affairs.

Clinical trials registration: This work follows the Consolidated Standards of Reporting Trials guidelines, and is registered per International Committee of Medical Journal Editors guidelines (Clinical Trial Registration Number NCT00482768).

\section{References}

1. Meyers DS, Clancy CM. Primary care: too important to fail. Ann Intern Med. 2009;150(4):272-273.

2. Margolius D, Bodenheimer T. Transforming primary care: from past practice to the practice of the future. Health Aff (Millwood). 2010; 29(5):779-784.

3. Grundy P, Hagan KR, Hansen JC, Grumbach K. The multi-stakeholder movement for primary care renewal and reform. Health Aff (Millwood). 2010;29(5):791-798.

4. Bodenheimer T, Pham HH. Primary care: current problems and proposed solutions. Health Aff (Millwood). 2010;29(5):799-805.

5. Nutting PA, Crabtree BF, Miller WL, Stange KC, Stewart E, Jaén C. Transforming physician practices to patient-centered medical homes: lessons from the national demonstration project. Health Aff (Millwood). 2011;30(3):439-445. 
6. Rittenhouse DR, Casalino LP, Shortell SM, et al. Small and mediumsize physician practices use few patient-centered medical home processes. Health Aff (Millwood). 2011;30(8):1-10.

7. Grumbach K, Mold JW. A health care cooperative extension service: transforming primary care and community health. JAMA. 2009;301(24):2589-2591.

8. Scutchfield FD. The cooperative medical extension program: trans lation of medical best practices to practicing primary care providers. Am J Prev Med. 2009;37(4):374-376.

9. Nagykaldi Z, Mold JW, Aspy CB. Practice facilitators: a review of the literature. Fam Med. 2005;37(8):581-588.

10. DeWalt D, Powell J, Mainwaring B, et al. Improving performance in Practice National Quality Improvement Team. In: Practice Coaching Program Manual. Princeton, NJ: Aligning Forces for Quality (AF4Q), George Washington University Medical Center; 2010.

11. Baskerville NB, Liddy C, Hogg W. Systematic review and metaanalysis of practice facilitation within primary care settings. Ann Fam Med. 2012;10(1):63-74

12. Hogg W, Baskerville N, Lemelin J. Cost savings associated with improving appropriate and reducing inappropriate preventive care: cost-consequences analysis. BMC Health Serv Res. 2005;5(1):20.

13. Parchman ML, Pugh JA, Culler SD, et al. A group randomized tria of a complexity-based organizational intervention to improve risk factors for diabetes complications in primary care settings: study protocol. Implement Sci. 2008;3:15.
14. Lanham HJ, McDaniel RR Jr, Crabtree BF, et al. How improving practice relationships among clinicians and nonclinicians can improve quality in primary care. Jt Comm J Qual Patient Saf. 2009;35(9):457-466.

15. Dogherty EJ, Harrison MB, Graham ID. Facilitation as a role and process in achieving evidence-based practice in nursing: a focused review of concept and meaning. Worldviews Evid Based Nurs. 2010;7(2):76-89.

16. Reid RJ, Coleman K, Johnson EA, et al. The Group Health medical home at year two: cost savings, higher patient satisfaction, and less burnout for providers. Health Aff (Millwood). 2010;29(5):835-843.

17. Gilfillan RJ, Tomcavage J, Rosenthal MB, et al. Value and the medical home: effects of transformed primary care. Am J Manag Care. 2010;16(8):607-614.

18. Peikes D, Zutshi A, Genevro JL, Parchman ML, Meyers DS. Early evaluations of the medical home: building on a promising start. Am J Manag Care. 2012;18(2):105-116.

19. Grumbach K, Bainbridge E, Bodenheimber T. Facilitating Improvement in Primary Care: The Promise of Practice Coaching. New York, NY: The Commonwealth Fund; 2012.

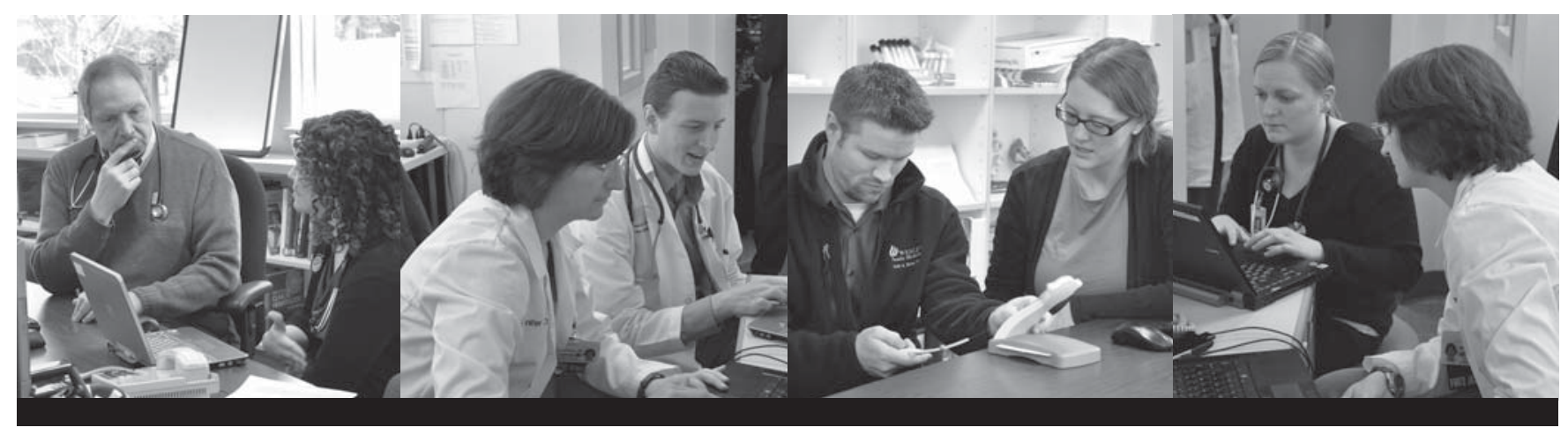

\section{Recruit, train, and retain preceptors}

Teaching Physician is an online, streamlined training program that answers questions and communicates regularly with preceptors on your behalf. It's a unique perk for both your program and your preceptors. 